http://jmscr.igmpublication.org/home/ ISSN (e)-2347-176x ISSN (p) 2455-0450

crossref DOI: https://dx.doi.org/10.18535/jmscr/v10i2.29

\title{
Replacing endoscopic colonoscopy with CT-colonography to improve patient experience during colorectal cancer screening
}

\author{
Author \\ Alzahrani Malik Ali \\ Senior Radiology Technologist
}

\section{Introduction}

Growth arising from the inner lining of the gastrointestinal tract such as colonic lipomas and colorectal polyps can be neoplastic or nonneoplastic with the potential to develop into adenomatous or cancerous lesions and subsequently grow into large tumours (Nallamothu \& Adler, 2011). The goal of screening or surveillance of colorectal cancer is to detect colorectal neoplasia or precancerous lesions in their early stages, so that they can be removed endoscopically through colonoscopy (polypectomy) or treated in order to reduce the risk of colorectal cancer development (GallegosOrozco \& Gurudu, 2010; Nallamothu \& Adler, 2011; Fyock \& Draganov, 2010). While early detection of solitary colorectal cancer lesions can be successfully resected before they develop into large tumours, continued surveillance following curative resection is important to prevent recurrence (Scheer \& Auer, 2009).

Cancer screening guidelines recommend routine screening for colorectal cancer and adenomatous neoplasias in asymptomatic adults aged 50 years or older including all adults with known inflammatory bowel disease and ulcerative colitis as well as Crohn's disease (National Institute for Health and Care Excellence-NICE, 2011;
Centres for Disease Control and PreventionCDC, 2011). This can be accomplished using faecal occult blood test (FOBT) also called faecal immunochemical test (FIT) done every 12 months, faecal DNA test done every 3 years, flexible sigmoidoscopy or computed tomography (CT) colonography (CTC) done every 5 years, and endoscopic colonoscopy done every 10 years (Heitman et al., 2010). However, the diagnosis of colorectal polyps and associated cancer has for the long-time been based on the more invasive colonoscopy or sigmoidoscopy procedure. These invasive procedures involve insertion of flexible endoscope tube through the anus and passed through the rectum to the entire colon while the gastroenterologist visualizes for the presence of colorectal neoplasias, polyps, and other abnormalities (Sharaf \& Ladabaum, 2013). As such, endoscopic colonoscopy has for the longtime remained a routine diagnostic modality of choice for colorectal cancer screening and surveillance by clinicians, policy makers, and national as well as regional or world health organizations.

The majority of colorectal neoplasias found during the routine colonoscopy work-ups can be successfully resected endoscopically by most gastroenterologists with adequate training 
(Gallegos-Orozco \& Gurudu, 2010). However, resecting some colorectal neoplasias during colonoscopy can be technically impractical due to their small size or luminal surface orientation. Furthermore, colonoscopic resection of some colorectal polyps is associated with an increased risk of complications, especially bleeding due to perforations or tears, and therefore, they are not routinely resected (Gallegos-Orozco \&Gurudu, 2010; Bujanda et al., 2010).

In endoscopic polypectomy, differential diagnosis of hyperplastic (benign) and adenomatous (malignant) colorectal polyps requires biopsy. In the advent of CTC, also called virtual colonoscopy, colorectal screening and subsequent endoscopic polypectomies have been made much easier and less risky. CTC can detect smaller polyps ranging from 6 to $9 \mathrm{~mm}$ in diameter, which are otherwise missed by the conventional optical colonoscopy (Kim et al., 2007). It is also excellent for evaluating the inflammation of pouches (diverticula, which usually form in the colorectal walls) and other symptoms suggestive of diverticular or inflammatory bowel disease.

There is poor compliance to colonoscopic cancer surveillance from the general population attributable to the invasive nature of the routine endoscopic colonoscopy. The non-invasive CTC is not only adequately accurate but also likely to improve patient compliance. As a CT scan technologist and a leader in a diagnostic radiology department, I find it important to move away from the conventional endoscopic colonoscopy to CTC in order to improve patient clinical experience during colorectal cancer screening. This paper, appraises the available published evidence on diagnostic and patient issues to justify the replacement of the routine colonoscopy with CTC.

\section{Literature Review}

Diagnostic utility of endoscopic colonoscopy versus CTC

The conventional optical colonoscopy is performed on an empty bowel to allow a clear view of the colorectal lumen. Since the invasive nature of colonoscopy or sigmoidoscopy causes considerable discomfort, sedation is usually required in patients who cannot tolerate (Loeve et al., 2013). On the other hand, CTC uses a lowdose CT scanning to obtain an interior view in 2and 3-dimensional images of the entire colon and rectum. It is also performed on an empty bowel though sedation is not required. Using a small narrow, flexible catheter or rectal tube, the colon is first distended by manual or automatic insufflation with room air or carbon dioxide gas (preferably automatic) to allow adequate visualization of a complete colonic lumen (Boellaard et al., 2013;-NICE, 2005). Prior to insufflation, a patient may be administered with an anticholinergic (antispasmodic) agent such as buscopan or glucagon to ease colonic spasm and abdominal discomfort (Park et al., 2007). CTC scan is then done while a patient is in supine and prone positions while holding the inhaled breath for about 20 seconds. Residual colonic fluids and faeces may conceal colonic polyps and, therefore, tagging the residual fluid and stool with contrast agent prior to the CTC scan is important in improving reader sensitivity (Summers, 2009; NICE, 2005).

The diagnostic accuracy of CTC versus the conventional endoscopic colonoscopy is important in clinical decision-making during the diagnosis of colorectal neoplasias. Several diagnostic test accuracy studies have demonstrated that CTC has sufficient sensitivity and specificity in detecting colorectal polyps. Selcuk et al. (2006) evaluated 48 patients who were at an increased risk for colorectal cancer with CTC followed by the routine endoscopic colonoscopy as the reference standard. CTC correctly depicted 19 of 22 colorectal polyps that were detected by the conventional colonoscopy which translated to a sensitivity of $86 \%$. Surprisingly, CTC depicted polyps that were greater than $10,6-9$ and $\leq 5 \mathrm{~mm}$ in diameter at accuracy levels of up to $100 \%$, $85 \%$, and $81 \%$, respectively; which translated to an overall sensitivity of $86 \%$ and a specificity of $98 \%$. This finding is consistent with that from a 
recent systematic review of nine studies (MartinLopez et al., 2014), which evaluated diagnostic utility between CTC and colonoscopy in the diagnosis of colorectal cancer. The summarised diagnostic accuracy evidence demonstrated that CTC exhibited a lower sensitivity in the detection of colorectal polyps that were $<6 \mathrm{~mm}$ in diameter but a higher sensitivity for polyps $>10 \mathrm{~mm}$ is size. The specificity of CTC is usually lower than that of routine colonoscopy. This is because the ability of CTC to differentiate stool from artifacts and tiny colorectal polyps is usually not as good as that of the conventional colonoscopy. Another previous systematic review and meta-analysis evaluated diagnostic accuracy of CTC versus endoscopic colonoscopy from 49 and 25 diagnostic studies, respectively; for the detection of colorectal cancer (Pickhardt et al., 2011). The CTC exhibited a sensitivity of $96.1 \% \quad(95 \%$ confidence interval-CI: $93.8 \%, 97.7 \%$ ) and there were no missed colorectal cancer cases when both cathartic and tagging agents were combined during bowel preparation. On the other hand, optical colonoscopy exhibited a sensitivity of 94.7\% (95\% CI: 90.4 - 97.2\%). Clearly, CTC is highly sensitive with adequate specificity for differential diagnosis of colorectal cancer. Given the relatively low prevalence of colorectal cancer worldwide (Haggar \& Boushey, 2009), primary CTC may be more suitable than the invasive optical colonoscopy for preliminary investigation of suspected colorectal cancer as well as for routine surveillance.

\section{Risks and patient experience during endoscopic colonoscopy versus CTC}

Patient clinical experience has a significant influence on their levels of satisfaction; yet understanding and addressing their attitudes towards their own healthcare is essential to improving the quality of their clinical experience, future clinical compliance and appropriate utilisation of medical resources (Tierney et al., 2015). Gastrointestinal endoscopy, especially colonography is a common diagnostic procedure for screening for adenomatous colorectal polyps that can potentially cause colorectal cancer. However, optical colonoscopy is associated with significant patient anxiety levels and apprehension (Tierney et al., 2015).

Insertion of the flexible colonoscope to a point close to the ileocaecal valve so that the entire caecum is visualized - a clinical phenomenon called caecal intubation - is widely recognised as one of intraprocedural indicators of a quality colonoscopy in both screening and non-screening settings (Schoenfeld \& Cohen, 2013; Ekkelenkamp et al., 2013; Bannert et al., 2012). Thus, the best colonoscopists are regarded as those with high caecal intubation rates (CIR), use less sedation, cause less abdominal discomfort and still able to locate more colorectal polyps (Ekkelenkamp et al., 2013; Bannert et al., 2012). When compared to the conventional colonoscopy, CTC has very minimal risk of perforating the colon since it does not require insufflation with room air or carbon dioxide, which increases colonic perforation risk (Kato et al., 2015; Zukiwskyj \& Arafat, 2016; de Gonzalez et al., 2010). A majority of people who undergo CTC actually do not have colorectal polyps or may be found to have diminutive polyps, which can be regarded as clinically insignificant (Rex, 2012). Therefore, CTC spares such patients from undergoing the invasive optical colonoscopy, which typically requires sedation. CTC further reduces the risk of complications from optical colonoscopy due to treatment with blood thinners or due to the presence of narrowed/obstructed bowel that can result in significant haemorrhage following colorectal perforations (Timothy et al., 2001). Another advantage of CTC is that it allows evaluation of the entire colon, even to the point where the conventional colonoscopy cannot reach, which occurs in 1 of 10 colonoscopic evaluations (Witte \& Enns, 2007). It can also detect other abnormalities outside of the colon and rectum, including early-stage malignancies in adjacent organs (Frentz \& Summers, 2006) and other clinical conditions, such as abdominal aortic 
aneurysms (Pickhardt et al., 2009). Lastly, while CTC uses low-radiation dose and therefore, there is a very slight chance of cancer and the diagnostic benefit of an accurate diagnosis far prevails over any risk of radiation-induced cancer. While endoscopic colonoscopy will remain the "gold standard" for colorectal cancer screening and endoscopic polypectomies, bowel preparation is a core determinant of its success in terms of sensitivity and accuracy (Harewood et al., 2003; Lebwohl et al., 2011). The quality of bowel cleansing prior to colonoscopy must be excellent to facilitate the detection of adenomatous lesions that are actually present. As such, poor bowel cleansing does not only reduce the detection rates of both small and large colorectal neoplasia but also prolong caecal intubation and withdrawal time (Harewood et al., 2003; Lebwohl et al., 2011; Jover et al., 2013). Yet, poor bowel preparation has remained a major challenge in performing an effective colonoscopy and unfortunately still occurs more often. Results from a previous randomized clinical trial (Froehlich et al., 2005), and data from a clinical outcomes research for endoscopic colonoscopies (Harewood et al., 2003) consistently indicate that suboptimal bowel preparation occurs in at least $25 \%$ of the cases. Patients often find bowel preparation as the worst and the most unpleasant part of the colonoscopy procedure; yet it is also a significant procedure for virtual colonoscopy. The colon-cleansing regimen often causes adverse effects, especially abdominal pain, cramping, bloating, nausea, and vomiting. There is some strong evidence that fear of bowel preparation is a key reason for low patient compliance for colonoscopic colorectal screening (Dykes \& Cash, 2008; Jones et al., 2008).

While addressing the safety and tolerability of regimens for bowel preparation may enhance patient compliance for colorectal cancer screening (Cohen et al., 2009), patients have generally poor attitudes towards the invasive nature of the conventional endoscopic colonoscopy. Although poor patient compliance to bowel preparation is common to both optical and virtual colonoscopy
(Gluecker et al., 2006), optical colonoscopy subjects patients to double suffering, that is; having to undergo the unpleasant bowel preparation and then the invasive endoscopic colonoscopy. Virtual colonoscopy using diagnostic imaging modalities, such as CTC and MR Colonography (MRC) eliminates the trouble of undergoing an invasive endoscopic colonoscopy procedure. So to speak, virtual colonoscopy has emerged as a more comfortable screening option for patients undergoing a comprehensive luminal screening of the colon and rectum. Hafeez et al. (2012) previously evaluated patient experiences of the non-invasive MRC versus the conventional endoscopic colonoscopy. The study enrolled 18 patients with known colonic inflammatory bowel disease-IBD $(\mathrm{n}=10)$ and those with clinically suspected colorectal neoplasia-non-IBD $(n=8)$. A majority of the patients complained of more abdominal discomfort during colonoscopy, which remarkably in IBD patient subgroup, which was associated with air insufflation and mechanical colonoscopic manipulation. Consequently, 10 patients (56\%) expressed an overall preference for the virtual colonoscopy using MRC compared to only 5 (28\%) who preferred the conventional colonoscopy. Reasons for preference of CTC as stated by the patients included less discomfort, speed of the test, safety, perceived diagnostic utility. However, for those who preferred the conventional colonoscopy stated its ability to take biopsies perceived to be of reliable diagnostic ability (Hafeez et al., 2012). In another previous survey study by Pooler et al., (2012), a total of 1417 consecutive cohort of adults scheduled to undergo CTC procedure in three disparate screening settings were assessed for their pre-test choices, experience, and satisfaction. The most significant reason for choosing CTC for screening was its non-invasive nature $(68.0 \%)$, no need for sedation $(63.1 \%)$, ability to sit/drive right after the test $(49.2 \%)$, avoidance of optical colonoscopy risks $(46.9 \%)$, and its ability to identifying extracolonic abnormalities (43.3\%). Furthermore, of a 
subgroup of patients $(\mathrm{n}=441)$, who had undergone both CTC and colonoscopy; a majority (77.1\%) preferred CTC while only $13.8 \%$ preferred the conventional colonoscopy (Pooler et al., 2012). By this account, CTC is clearly the most acceptable diagnostic modality for colorectal cancer screening and should, therefore replace the conventional optical colonoscopy. Actually, there is increasing effort towards dissemination, training and remuneration of non-invasive CTC technologists into community practices for colorectal cancer screening (Summers, 2009).

\section{Recommendations for Practice}

Routine screening for colorectal cancer and adenomatous polyps is recommended for patients with a personal history of IBD, Crohn's disease and ulcerative colitis as well as a family history of adenomatous/cancerous polyps. Given that colorectal cancer risk increases with age, asymptomatic adults aged 50 years and older should be screened every 10 years (NICE, 2011; CDC, 2011). There are several cancer screening methods, with different sensitivity to detect colorectal cancer, which include FOBT or FIT, flexible sigmoidoscopy, optical colonoscopy, CTC, barium enema with air contrast, and stool DNA testing (Sharaf \& Ladabaum, 2013). However, all except FOBT or FIT and stool DNA testing tests have proven ability to detect cancercausing colorectal polyps (CDC, 2011).

From the reviewed literature, both endoscopic colonoscopy and CTC can aid in the visualization of colorectal polyps and therefore, useful for colorectal cancer diagnosis and screening. Colonoscopy is considered the gold standard of all colorectal cancer screening methods owing to its ability to view the entire colon and both detect and remove polyps during the same procedure. While CTC could be less costly than the conventional colonoscopy, extra costs may be involved in the workup of extra-colonic findings (Kimberly et al., 2009), which provides opportunities for additional cancer screening. It also provides a more safe option for surveillance after curative colorectal cancer resection (Scheer \& Auer, 2009). Therefore, poor compliance of the general population to optical colonoscopy surveillance warrants a review of the current clinical practice guidelines and national policies on colorectal cancer screening strategies. CT is currently the most common imaging modality in many hospitals worldwide, though its application in CTC is less common, possibly due to low turnouts of the general population for colorectal cancer screening.

Implementation of CTC requires training of CT technologists in two important aspects: pre- and intra-procedure requirements. First, CT technologists should work in collaboration with referring physicians to administer to the patient the most efficacious bowel cleansing regimens for effective bowel preparation. Given that, bowel preparation is the most unpleasant procedure, CT technologists and physicians should administer their CTC candidates with bowel-cleansing regimens, which have little side effects established by clinical evidence base. Secondly, while CT technologists should use low-dose CTC, they should be adequately trained on the effective dose, which varies from one patient to another and therefore, should learn to use individualized doses for each patient.

\section{Conclusion}

Endoscopic colonoscopy is hitherto considered the gold standard for colorectal cancer screening owing to its ability to view the entire colon, detect polyps and allow their excision during the same procedure. CTC is the best alternative to optical colonoscopy for screening colorectal neoplasms and cancer. Its relatively high sensitivity and adequate specificity in detecting colorectal polyps including extra-colorectal abnormalities in adjacent organs, its non-invasive nature, its low risks to cause colorectal perforations coupled with its relatively low radiation dose make it suitable to replace the optical colonoscopy in colorectal cancer diagnosis and screening or surveillance. However, effective bowel preparation is a key 
determinant of the effectiveness of colonoscopy as well as CTC. Given that poor patient compliance to bowel preparation is a challenge to both optical and virtual colonoscopy, clinicians should establish the best colon-cleansing regimens that are efficacious with minimal side effects to enhance compliance. To enhance colorectal surveillance, national health policies require amendments to enhance patient information and access to CTC for routine colorectal screening. CT radiographers should receive adequate training on how to perform and effective CTC to ensure good patient experience.

\section{References}

1. BANNERT, C. et al., 2012. Sedation in Screening Colonoscopy: Impact on Quality Indicators and Complications [online]. The American Journal of Gastroenterology, 107(12), pp.1837-1848. [viewed 9 April 2016]. [viewed 9 April 2016]. Available from:

http://www.ncbi.nlm.nih.gov/pubmed/23147 522

2. BOEllaARD, T. N. et al., 2013. Colon Distension and Scan Protocol for CTColonography: An Overview [online]. European Journal of Radiology, 82(8), pp.1144-1158. [viewed 9 April 2016]. [viewed 9 April 2016]. Available from: http://www.ncbi.nlm.nih.gov/pubmed/22154 604

3. BUJANDA, L. et al. 2010. Malignant Colorectal Polyps [online]. World Journal of Gastroenterology: WJG, 16(25), pp.31033111. [viewed 9 April 2016]. Available from:

http://www.ncbi.nlm.nih.gov/pmc/articles/P MC2896747/

4. CENTERS FOR DISEASE CONTROL AND PREVENTION, 2011. CDC Colorectal Cancer Screening Guidelines. [online] Cdc.gov. [viewed 9 April 2016]. Available at: http://www.cdc.gov/cancer/colorectal/basic_ info/screening/guidelines.htm [Accessed 6 Apr. 2016].

5. COHEN, L. B. ET AL., 2009. Current Issues in Optimal Bowel Preparation: Excerpts From a Roundtable Discussion Among Colon-Cleansing Experts [online]. Gastroenterology \& Hepatology, 5(11 Suppl 19), pp.3-11. [viewed 9 April 2016]. Available from: http://www.ncbi.nlm.nih.gov/pmc/articles/P MC2886377/

6. de GONZALEZ, A. B., KIM, K. P., \& YEE, J. 2010. CT Colonography: Perforation Rates and Potential Radiation Risks [online]. Gastrointestinal endoscopy clinics of North America, 20(2), 279-291. [viewed 9 April 2016]. Available from: http://www.ncbi.nlm.nih.gov/pubmed/20451 817

7. DYKES, C., \& CASH, B. D. 2008. Key Safety Issues of Bowel Preparations for Colonoscopy and Importance of Adequate Hydration [online]. Gastroenterology Nursing, 31(1), pp.30-35; quiz 36-37. [viewed 9 April 2016]. Available from: http://www.ncbi.nlm.nih.gov/pubmed/18300 822

8. EKKELENKAMP, V. E. et al., 2013. Patient Comfort and Quality in Colonoscopy [online]. World Journal of Gastroenterology: WJG, 19(15), pp.23552361. [viewed 9 April 2016]. Available from:

http://www.ncbi.nlm.nih.gov/pubmed/23613 629

9. FRENTZ, S. M., \& SUMMERS, R. M. 2006. Current Status of CT Colonography [online]. Academic Radiology, 13(12), pp.1517-1531. [viewed 9 April 2016]. Available from: http://www.ncbi.nlm.nih.gov/pmc/articles/P MC1764496/

10. FROEHLICH, F. et al., 2005. Impact of Colonic Cleansing On Quality And Diagnostic Yield of Colonoscopy: the 
European Panel of Appropriateness of Gastrointestinal Endoscopy European multicenter study [online]. Gastrointestinal Endoscopy, 61(3), pp.378-384. [viewed 9 April 2016]. Available from: http://www.ncbi.nlm.nih.gov/pubmed/15758 907

11. FYOCK, C. J., \& DRAGANOV, P. V. 2010. Colonoscopic Polypectomy and Associated Techniques [online]. World Journal of Gastroenterology: WJG, 16(29), pp.3630-3637. [viewed 9 April 2016]. Available from: http://europepmc.org/abstract/MED/206773 34

12. GALLEGOS-OROZCO, J. F., \& GURUDU, S. R. 2010. Complex Colon Polypectomy [online]. Gastroenterology \& Hepatology, 6(6), pp.375-382. [viewed 9 April 2016]. Available from: http://www.ncbi.nlm.nih.gov/pmc/articles/P MC2920588/

13. GLUECKER, T. M. et al., 2003. Colorectal Cancer Screening with CT Colonography, Colonoscopy, and Double-Contrast Barium Enema Examination: Prospective Assessment of Patient Perceptions and Preferences. Radiology, 227(2), pp.378-384. [viewed 9 April 2016]. Available from: http://www.ncbi.nlm.nih.gov/pubmed/12732 696

14. HAFEEZ, R. et al., 2012. Patient Experiences of MR Colonography and Colonoscopy: A Qualitative Study [online]. The British Journal of Radiology, 85(1014), pp.765-769. [viewed 9 April 2016]. Available from: http://www.ncbi.nlm.nih.gov/pubmed/22010 031

15. HAGGAR, F. A., \& BOUShEY, R. P. 2009. Colorectal Cancer Epidemiology: Incidence, Mortality, Survival, and Risk Factors [online]. Clinics in Colon and Rectal Surgery, 22(4), pp.191-197. [viewed 9 April 2016].

from: http://www.ncbi.nlm.nih.gov/pubmed/21037 809

16. HAREWOOD, G. C., SHARMA, V. K., \& DE GARMO, P. 2003. Impact of Colonoscopy Preparation Quality on Detection of Suspected Colonic Neoplasia [online]. Gastrointestinal Endoscopy, 58(1), pp.76-79. [viewed 9 April 2016]. Available from:

http://www.giejournal.org/article/S00165107\%2803\%2901305-1/abstract

17. HEITMAN, S. J. et al., 2010. Colorectal Cancer Screening for Average-Risk North Americans: An Economic Evaluation [online]. PLoS Medicine, 7(11), e1000370. [viewed 9 April 2016]. Available from: http://www.ncbi.nlm.nih.gov/pubmed/21124 887

18. JONES, R. M. et al., 2010. Patient-Reported Barriers to Colorectal Cancer Screening: A Mixed-Methods Analysis [online]. American Journal of Preventive Medicine, 38(5), pp.508-516. [viewed 9 April 2016]. Available from: http://www.ncbi.nlm.nih.gov/pubmed/20409 499

19. JOVER, R. et al. 2013. Modifiable Endoscopic Factors That Influence the Adenoma Detection Rate in Colorectal Cancer Screening Colonoscopies [online]. Gastrointest Endosc, 77(3), pp.381389.e381. [viewed 9 April 2016]. Available from:

http://www.ncbi.nlm.nih.gov/pubmed/23218 945

20. KATO, T. et al. 2015. Iatrogenic Colonic Perforation due to Computed Tomographic Colonography [online]. Case Reports in Gastroenterology, 9(2), 171-178. [viewed 9 April 2016]. Available from: https://www.karger.com/Article/FullText/43 0947

21. KIM, D. H. et al., 2007. CT Colonography versus Colonoscopy for the Detection of Advanced Neoplasia [online]. New England 
Journal of Medicine, 357(14), 1403-1412.

[viewed 9 April 2016]. Available from: http://www.nejm.org/doi/full/10.1056/NEJ

Moa070543

22. KIMBERLY, J. R. et al., 2009. Extracolonic Findings at Virtual Colonoscopy: An Important Consideration in Asymptomatic Colorectal Cancer Screening [online]. Journal of General Internal Medicine, 24(1), pp.69-73. [viewed 9 April 2016]. Available from:

http://www.ncbi.nlm.nih.gov/pubmed/18958 531

23. LEBWOHL, B. et al., 2011. The Impact of Suboptimal Bowel Preparation on Adenoma Miss Rates and the Factors Associated with Early Repeat Colonoscopy [online]. GastrointestEndosc, 73(6), pp.1207-1214. [viewed 9 April 2016]. Available from: http://www.ncbi.nlm.nih.gov/pubmed/21481 857

24. LOEVE, A. J., FOCKENS, P., \& BREEDVELD, P. 2013. Mechanical Analysis Of Insertion Problems And Pain During Colonoscopy: Why Highly SkillDependent Colonoscopy Routines Are Necessary In The First Place And How They May Be Avoided [online]. Canadian Journal of Gastroenterology, 27(5), pp.293302. [viewed 9 April 2016]. Available from:

http://www.ncbi.nlm.nih.gov/pubmed/23712 305

25. MARTIN-LOPEZ, J. E. et al., 2014. Comparison of the accuracy of CT colonography and colonoscopy in the diagnosis of colorectal cancer [online]. Colorectal Disease, 16(3), pp.O82-89. [viewed 9 April 2016]. Available from: http://www.ncbi.nlm.nih.gov/pubmed/24299 052

26. NALlAMOTHU, G., \& ADLER, D. G. 2011. Large Colonic Lipomas [online]. Gastroenterology \& Hepatology, 7(7), pp.490-492. [viewed 9 April 2016].
Available

from:

http://www.ncbi.nlm.nih.gov/pmc/articles/P MC3264900/

27. NATIONAL INSTITUTE FOR HEALTH AND CARE EXCELLENCE, 2005. Computed tomographic colonography (virtual colonoscopy) | Guidance and guidelines | NICE. [online] Nice.org.uk. [viewed 9 April 2016]. Available at: https://www.nice.org.uk/guidance/ipg129

28. NATIONAL INSTITUTE FOR HEALTH AND CARE EXCELLENCE, 2011. Colonoscopic surveillance for preventing colorectal cancer in adults with ulcerative colitis, Crohn's disease or adenomas | 1Guidance | Guidance and guidelines | NICE. [online] Nice.org.uk. [viewed 9 April 2016]. Available at: https://www.nice.org.uk/guidance/cg118/ch apter/1-Guidance [Accessed 6 Apr. 2016].

29. PARK, S. H. et al. 2007. Fundamental Elements for Successful Performance of CT Colonography (Virtual Colonoscopy) [online]. Korean Journal of Radiology, 8(4), pp.264-275. [viewed 9 April 2016]. Available from: http://www.ncbi.nlm.nih.gov/pmc/articles/P MC2627155/

30. PICKHARDT, P. J. et al., 2011. Colorectal Cancer: CT Colonography and Colonoscopy for Detection-Systematic Review and Meta-Analysis [online]. Radiology, 259(2), pp.393-405. [viewed 9 April 2016]. Available from: http://pubs.rsna.org/doi/abs/10.1148/radiol.1 1101887

31. PICKHARDT, P. J. et al. 2009. CT Colonography To Screen For Colorectal Cancer And Aortic Aneurysm In The Medicare Population: Cost-Effectiveness Analysis [online]. American Journal of Roentgenology, 192(5), pp.1332-1340. [viewed 9 April 2016]. Available from: http://www.ncbi.nlm.nih.gov/pubmed/19380 558 
32. Pooler, B. D. et al., 2012. Screening CT Colonography: Multicenter Survey of Patient Experience, Preference, and Potential Impact on Adherence [online]. American Journal of Roentgenology, 198(6), pp.1361-1366. [viewed 9 April 2016]. Available from: http://www.ncbi.nlm.nih.gov/pubmed/22623 549

33. REX, D. K. 2012. Risks and Potential Cost Savings of Not Sending Diminutive Polyps for Histologic Examination [online]. Gastroenterology \& Hepatology, 8(2), pp.128-130. [viewed 9 April 2016]. Available from: http://www.ncbi.nlm.nih.gov/pmc/articles/P MC3317511/

34. SCHEER, A., \& AUER, R. A. C. 2009. Surveillance after Curative Resection of Colorectal Cancer [online]. Clinics in Colon and Rectal Surgery, 22(4), 242-250. [viewed 9 April 2016]. Available from: http://www.ncbi.nlm.nih.gov/pmc/articles/P MC2796101/

35. SCHOENFELD, P. S., \& COHEN, J. 2013. Quality Indicators for Colorectal Cancer Screening for Colonoscopy [online]. Techniques in gastrointestinal endoscopy, 15(2), pp.59-68. [viewed 9 April 2016]. Available from: http://www.ncbi.nlm.nih.gov/pmc/articles/P MC3790322/

36. SELCUK, D. et al., 2006. Comparison of Virtual Colonoscopy with Conventional Colonoscopy in Detection of Colorectal Polyps [online]. Turkish Journal of Gastroenterology, 17(4), pp.288-293. [viewed 9 April 2016]. Available from: http://www.ncbi.nlm.nih.gov/pubmed/17205 408

37. SHARAF, R. N., \& LADABAUM, U. 2013. Comparative Effectiveness and CostEffectiveness of Screening Colonoscopy vs. Sigmoidoscopy and Alternative Strategies.
American Journal of Gastroenterology 108(1), pp.120-132. [viewed 9 April 2016]. Available from: http://www.ncbi.nlm.nih.gov/pubmed/23247 579

38. SUMMERS, R. 2009. The Elephant in the Room: Bowel Preparation for CT Colonography Editorial for Academic Radiology article 08410R1 [online]. Academic radiology, 16(7), pp.777-779. [viewed 9 April 2016]. Available from: http://www.ncbi.nlm.nih.gov/pmc/articles/P MC2754302/

39. TIERNEY, M. et al., 2015. What Do Patients Want From Their Endoscopy Experience? The Importance of Measuring and Understanding Patient Attitudes to Their Care [online]. Frontline Gastroenterology. 0, pp1-8. [viewed 9 April 2016]. Available from: http://fg.bmj.com/content/early/2015/06/03/ flgastro-2015-100574

40. TIMOTHY, S. K. et al., 2001. Colonoscopy in the Patient Requiring Anticoagulation [online]. Dis Colon Rectum, 44(12), 18451848; discussion, 1848-1849. [viewed 9 April 2016]. Available from: http://www.ncbi.nlm.nih.gov/pubmed/11742 172

41. WITTE, T. N., \& ENNS, R. 2007. The difficult colonoscopy. Canadian Journal of Gastroenterology, 21(8), pp.487-490 [online]. [viewed 9 April 2016]. Available from: http://www.ncbi.nlm.nih.gov/pmc/articles/P MC2657972/

42. ZUKIWSKYJ, M., \& ARAFAT, Y. 2016. Case Report: Rectal perforation during CT colonography [online]. F1000Research, 5, 299. [viewed 9 April 2016]. Available from: http://www.ncbi.nlm.nih.gov/pmc/articles/P MC4805160. 